Randomized Study

\title{
Effect of Thoracic Epidural Analgesia on Pro- inflammatory Cytokines in Patients Subjected to Protective Lung Ventilation During Ivor Lewis Esophagectomy
}

Khaled M. Fares, MD, Sahar A. Mohamed, MD, Hesham M. Hamza, MD, Douaa M. Sayed, MD, and Diab F. Hetta, Msc

From: South Egypt Cancer Institute, Assuit University,

Egypt

Dr. Fares is Associate Professor of Anesthesia and Pain Management, South Egypt Cancer Institute, Assuit University, Egypt. Dr. Mohamed is Associate Professor of Anesthesia and

Pain Management, South Egypt Cancer Institute, Assuit University, Egypt. Dr. Hamza is Associate Professor of Surgical Oncology, South Egypt Cancer Institute, Assuit University, Egypt.

Dr. Sayed is Associate Professor

of Clinical Pathology, South Egypt Cancer Institute, Assuit University, Egypt. Dr. Hetta is Assistant Lecturer of Anesthesia and Pain Management, South

Egypt Cancer Institute, Assuit University, Egypt

Address Correspondence: Diab Fuad Hetta, MSc Assistant Lecturer of Anesthesia and Pain Management

South Egypt Cancer Institute Assuit University, Egypt E-mail:

diabhetta25@gmail.com

Disclaimer: There was no external funding in the preparation of this manuscript. Conflict of interest: Each author certifies that he or she, or a member of his or her immediate

family, has no commercial association (i.e., consultancies, stock ownership, equity interest, patent/licensing arrangements, etc.) that might pose a conflict of interest in connection with the submitted manuscript.

Manuscript received: 12-11-2013 Revised manuscript received: 03-02-2014

Accepted for publication: 03-10-2014

Free full manuscript: www.painphysicianjournal.com
Background: Thoracic epidural analgesia (TEA) has a well-known effect on neurohormonal response. Attenuation of stress response by post-operative epidural analgesia has shown beneficial effects such as lower pain scores and less immunological alterations.

Objectives: Investigation of the combined effects of TEA and protective lung ventilation on proinflammatory cytokines and patients' outcome after Ivor Lewis esophagectomy.

Study Design: A randomized controlled study.

Setting: Academic medical center.

Methods: Thirty patients of the American Society of Anesthesiologists (ASA) I and II were randomly allocated into 2 groups: $G 1(n=15)$ patients received general anesthesia and were

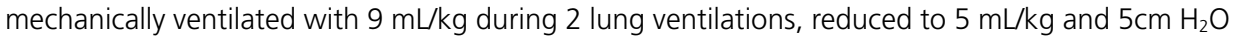
positive end expiratory pressure (PEEP) during one lung ventilation (OLV) or GII) ( $n=15)$ patients received TEA and the same general anesthesia and mechanical ventilation used in G1. Assessment parameters included hemodynamics, pain severity, total analgesic consumption, and measurement of interleukins (IL) (IL-6 and IL-8) at baseline time after anesthetic induction ( $\mathrm{T}_{\text {Baseline, }}$ ); at the end of the abdominal stage of the operation $\left(T_{\mathrm{Abdo}},\right)_{1} ; 15$ minutes after initiation and at the end of OLV (ToLv $\left.{ }_{15}\right)$ and (Tolv End $)$ respectively; one and 20 hours after the end of the surgical procedure ( $T_{\text {postop } 1}$ and $\left.T_{\text {Postop20 }}\right)$, respectively, and patient's outcome also recorded.

Results: There was a significant reduction in mean arterial blood pressure (MAP) and pulse rate in Gll during the intraoperative period, at $\mathrm{T}_{\mathrm{abdo}}, \mathrm{T}_{\mathrm{olv} 15}$, and $\mathrm{T}_{\text {olv End }}(P<0.05)$. The mean of systolic blood pressure (SBP) values were significantly lower in Gll over all 3 post-operative days $(P=0.001)$, and the mean diastolic blood pressure (DBP) showed a significant reduction in Gll for 16 hours post-operatively $(P=0.001)$. The mean of heart rate values showed a significant reduction in $\mathrm{Gll}$ over all 3 post-operative days in comparison to $\mathrm{GI}(P=0.001)$. The mean resting and dynamic VAS scores were significantly reduced in Gll at all time periods studied in comparison to $\mathrm{G} 1(P=0.001)$. The daily PCA morphine consumption was markedly decreased in Gll compared to Gl in the first 3 days post-operatively $(P=0.001)$. There were significant reductions in blood level of IL- 6 and IL-8 in Gll compared to $\mathrm{G} 1$ over the entire study period $(P<0.05)$. There were no significant differences in post-operative adverse effects between the 2 groups $(P>0.05)$. The duration of stay in PACU was significantly decreased in GII (10 \pm 2 days) compared to $\mathrm{Gl}(15 \pm 3$ days) $(P=0.001)$.

Limitations: This study is limited by its sample size.

Conclusion: Our study concluded that TEA reduced the systemic pro-inflammatory response and provided optimal post-operative pain relief. Although there were no significant differences in adverse events, there was a trend towards improved outcome. Further clinical studies with larger numbers of patients are required.

Key words: Esophagectomy, one lung ventilation, thoracic epidural analgesia proiflammatory cytokines

Pain Physician 2014; 17:305-315 
$\mathrm{T}$ he prognosis of esophageal cancer is generally poor because of its biological aggressiveness and anatomical characteristics. In order to improve the prognosis, an extended radical esophagectomy with radical lymphadenectomy is often performed; however, this treatment modality may also increase the amount of surgical stress $(1,2)$.

Esophagectomy is associated with marked perioperative morbidity and mortality, with rates up to $60 \%$ and $14 \%$ reported, respectively (3).

Multiple risk factors are responsible, including the stage of the tumor at presentation, the critical blood supply of the esophagus, and the hospital volume (number of yearly cases). The extensively released proinflammatory cytokines during esophagectomy play a crucial role in post-operative morbidity, especially postesophagectomy acute lung injury (ALI) (4).

The current anesthetic practice in esophagectomy is one lung ventilation (OLV) to facilitate surgical exposure. Anesthesiologists are accustomed to giving the same tidal volume $\left(\mathrm{V}_{\mathrm{T}}\right)$ during OLV to avoid atelectasis and hypoxemia but this was associated with a marked increase in pro-inflammatory cytokines (5).

The pro-inflammatory cytokines are released in part from the lung during isolation and from the extensive tissue destruction, the combination of both factors acts synergistically to cause changes in the immune response (4).

Previous studies used a small $\mathrm{V}_{\mathrm{T}}$ and $5 \mathrm{~cm} \mathrm{H}_{2} \mathrm{O}$ positive end expiratory pressure (PEEP) and they found a decreased release of pro-inflammatory cytokines without adverse effects (4).

Thoracic epidural analgesia (TEA) has a well-known effect on neurohormonal response. Attenuation of the stress response by post-operative epidural analgesia (EA) has shown beneficial effects such as lower pain scores and less immunological alterations (6).

A neuroendocrine response blunted by epidural anesthesia could affect post-operative immune function because the immune and nervous systems bidirectionally communicate and influence each other (7).

In upper abdominal or major surgery the effect of epidural anesthesia and analgesia on attenuation of the stress response and preservation of immune function is controversial $(8,9)$.

So the aim of our study was to investigate the combined effects of TEA and protective lung ventilation on pro-inflammatory cytokines and patients' outcome after Ivor Lewis esophagectomy.

\section{Methods}

This randomized prospective study was approved by the local ethics committee of the South Egypt Cancer Institute, Assiut University, Egypt. After written informed consent, 30 patients, American Society of Anesthesiologists (ASA) 1 and II (age, 20 - 60 years) scheduled for elective Ivor Lewis esophagectomy, were enrolled in this study.

Patients with New York Heart Association (NYHA) class III or IV, pre-existing chronic obstructive pulmonary disease with forced expiratory volume in one second (FEV1) less than $80 \%$ of predicted and/or FEV1 over forced vital capacity (FVC) ratio less than 0.7 , chronic renal failure (serum creatinine $>2 \mathrm{mg} / \mathrm{dl}$ ), altered liver function (Child-Pugh class B or more), preoperative corticosteroid treatment during the month before inclusion, bleeding diathesis, infection at the site of epidural catheter insertion, and allergy to the studied drugs were excluded from the study.

Patients were evaluated by posterioanterior (PA) view chest $x$ - ray, pulmonary function tests, 12 leads electrocardiography (ECG) recording, and arterial blood gas ( $A B G)$. Patients were taught how to evaluate their own pain intensity using the Visual Analogue Scale (VAS), scored from 0 to 10 (where $0=$ no pain and $10=$ the worst pain imaginable) and how to use patient controlled analgesia (PCA).

The night before surgery, oral diazepam $10 \mathrm{mg}$ and ranitidine $50 \mathrm{mg}$ were given. Upon arrival at the operating room, peripheral venous line, subclavian vein, and radial artery catheters were established. Lactated ringer's solution $10 \mathrm{~mL} / \mathrm{kg}$ was infused 10 minutes before the initiation of anesthesia. Monitoring probes (ECG, invasive blood pressure, $\mathrm{O}_{2}$ saturation $\left[\mathrm{SPO}_{2}\right]$, and temperature) were applied.

Patients were randomly allocated into 2 groups ( $n$ $=15$ ) by using opaque sealed envelopes containing a computer generated randomization schedule.

Group I (G1, $n=15)$ : patients received general anesthesia and were mechanically ventilated with $9 \mathrm{~mL} / \mathrm{kg}$ during 2 lung ventilations, reduced to $5 \mathrm{~mL} / \mathrm{kg}$ and $5 \mathrm{~cm}$ $\mathrm{H}_{2} \mathrm{O}$ PEEP during OLV.

Group II (GII, $n=15)$ : patients received TEA and the same general anesthesia and mechanical ventilation used in G1.

Under strict aseptic precautions, thoracic epidural was performed for patients in GIl using a 16-gauge Touhy epidural needle by a paramedian approach. TheT5-T6 or T6-T7 interspace was chosen for the injec- 
tion. The procedure was done under sedation by IV administration of $50 \mu \mathrm{g}$ fentanyl and $2 \mathrm{mg}$ midazolam. The epidural space was identified by the loss of resistance technique. A test dose of ( $3 \mathrm{~mL}$ ) $2 \%$ lidocaine with 1: 200,000 adrenaline was given after the placement of the epidural catheter. After a negative response, epidural bolus dose of $0.1 \mathrm{~mL} / \mathrm{kg}$ of $0.125 \%$ bupivacaine + fentanyl $15 \mu \mathrm{g} / \mathrm{mL}$ was administered, the epidural was considered to be adequately working if there was decreased pin prick sensation at the expected dermatomal level, then the bolus dose was followed by continuous infusion of $0.1 \mathrm{~mL} / \mathrm{kg} / \mathrm{hr}$ of $0.125 \%$ bupivacaine + fentanyl $10 \mu \mathrm{g} / \mathrm{mL}$ until the end of surgery. Continuous infusion of $0.1 \mathrm{~mL} / \mathrm{kg} / \mathrm{hr}$ of $0.125 \%$ bupivacaine + fentanyl $5 \mu \mathrm{g} / \mathrm{ml}$ was started at admission in the postanesthesia care unit (PACU) and continued for 72 hours post-operatively.

General anesthesia was induced by IV fentanyl 2 $\mu \mathrm{g} / \mathrm{kg}$ and propofol $1-2 \mathrm{mg} / \mathrm{kg}$. Tracheal intubation was facilitated by cisatracurium $0.15 \mathrm{mg} / \mathrm{kg}$. A doublelumen tube (Rush, Bronchopart, France) was inserted under guidance of fiberoptic bronchoscopy, then, general anesthesia was maintained with isoflurane and cisatracurium $0.03 \mathrm{mg} / \mathrm{kg}$ every 30 minutes. Hypotension was defined as a $20 \%$ decrease in systolic blood pressure from baseline and was treated with IV boluses of ephedrine $0.1 \mathrm{mg} / \mathrm{kg}$ and normal saline of $5 \mathrm{ml} / \mathrm{kg}$. The same doses were repeated as required.

Bradycardia was defined as heart rate slower than 50 beats/min. or as inappropriately slow heart rate despite hypotension and was treated with atropine 0.01 $\mathrm{mg} / \mathrm{kg}$.

The respiratory rate was adjusted to keep end tidal carbon dioxide (ETCO2) between 35 and $45 \mathrm{mmHg}$ throughout anesthesia. The initial inspired oxygen fraction (FIO2) was 0.5 using oxygen and air mixture and was increased if necessary to keep peripheral arterial oxygen saturation (SPO2) greater than $90 \%$. In case of perioperative hypoxemia, the only treatment used was an increase in (FIO2). Heart rate, MAP, oxygenation index, partial pressure of arterial carbon dioxide tension ( $\mathrm{PaCO} 2$ ), and peak inspiratory pressure and plateau pressure were obtained at baseline time after anesthetic induction ( $\mathrm{T}_{\text {Baseline }}$ ), at the end of the $\mathrm{ab}$ dominal stage of the operation $\left(T_{A b d o}\right), 15$ minutes after initiation, and at the end of OLV ( $T_{\text {OLV 15 }}$ ) and ( $T_{\text {olv End }}$ ), respectively. Extubation was performed when patients met the following extubation criteria: temperature greater than $36^{\circ} \mathrm{C}$, MAP greater than $70 \mathrm{mmHg}$, arterial oxygen partial pressure ( $\mathrm{PaO} 2 / \mathrm{FIO} 2)$ ratio greater than $200 \mathrm{mmHg}$, hemoglobin level greater than $8 \mathrm{~g} / \mathrm{dl}$, ratio of respiratory frequency to tidal volume less than 105 breaths/min L under $10 \mathrm{~cm} \mathrm{H} 20$ pressure support and 5 $\mathrm{cm} \mathrm{H}_{2} \mathrm{O}$ (PEEP), adequate cough during suctioning, and adequate recovery from muscle relaxants. Duration of surgery, transfusion requirements, and urine output were recorded.

Surgery was done by the same experienced surgeons who were blinded to the strategy used. Surgical procedures included a median

laparotomy with construction of a neoesophagus using the stomach and a right thoracotomy in the lateral decubitus position allowing subtotal esophagectomy combined with 2 fields lymphadenectomy and esophagogastric anastomosis through the thoracic route.

At the end of the operation, patients were transferred to PACU and were monitored with ECG, invasive blood pressure, and pulse oximeter. Central venous pressure (CVP) was measured every 2 hours. Urine output, surgical drains, and intercostal tubes were observed and calculated. ABG analysis was done every 12 hours and chest x-ray every 24 hours.

Post-operative analgesia comprised PCA with an initial morphine bolus of $0.1 \mathrm{mg} / \mathrm{kg}$ once pain was expressed by the patient or if VAS $\geq 3$, followed by 1 $\mathrm{mg}$ boluses with a lockout period of 5 minutes. VAS and post-operative consumption of analgesic in the form of PCA morphine was recorded for 72 hours post-operative. The patients were followed up in their stay in PACU for detection of any post-operative complications.

\section{Technique of Measurement}

Five samples of venous blood were obtained for measurement of IL- 6 and IL- 8 at $\mathrm{T}_{\text {Baseline, }} \mathrm{T}_{\text {Abdo, }} \mathrm{T}_{\text {oLv End, }}$ $T_{\text {Postop1, and }} T_{\text {postop20 }}$ one and 20 hours after the end of the surgical procedure respectively.

Blood samples were collected into non-pyrogenic, sterile falcon tubes. Serum was separated by cold centrifugation of the blood at $1,500 \mathrm{~g}$ for 10 minutes and stored at $-70^{\circ} \mathrm{C}$. To improve the homogeneity of measurements, all of the samples were analyzed at the same time with the same assay reagents by the same laboratory technician blinded to the groups. Serum IL-6 and IL-8 were measured using enzyme-linked immunosorbent assay (human IL-6 and IL-8 ELISA KIT, AVIBION, Ani Biotech oy, Finland). The lower detection limits for these kits are $7 \mathrm{pg} / \mathrm{mL}$ and $2 \mathrm{pg} / \mathrm{mL}$, respectively. 


\section{Statistical Analysis}

Data analysis was done using SPSS version 20 (Statistical package for social science). The minimal requirement for the calculated sample size was 11 patients per group to detect a difference in mean of IL-6 concentration of $33 \%$, an estimated SD of $79.5 \%$, with a power of $80 \%$ and a $5 \%$ risk of type I error. Qualitative data was described by numbers and percentages, where quantitative data were described using mean and standard deviation. Chi-square test was used to test the relationship between qualitative variables and independent samples t-test was used to compare between 2 groups of quantitative data. $P<0.05$ was considered significant.

\section{Results}

There were no significant differences among the 2 groups in demographic data and patient characteristics $(P>0.05)$ (Table 1).

In regard to intraoperative data there was a signifi-

Table 1. Demographic data and patients' characteristics.

\begin{tabular}{|c|c|c|c|}
\hline & GI $(n=15)$ & GII $(n=15)$ & $P$ value \\
\hline Age, yr & $59.2 \pm 6.5$ & $53.4 \pm 10.4$ & 0.088 \\
\hline Gender, $M / F$ & $11 / 4$ & $12 / 3$ & 0.501 \\
\hline BMI, $\mathrm{kg} / \mathrm{m}^{2}$ & $22.1 \pm 3.3$ & $23.9 \pm 1.5$ & 0.066 \\
\hline \multicolumn{4}{|l|}{ ASA, n (\%) } \\
\hline I & $8(53.3)$ & $9(60.0)$ & \multirow{2}{*}{0.501} \\
\hline II & $7(46.7)$ & $6(40.0)$ & \\
\hline \multicolumn{4}{|l|}{ NYHA, n (\%) } \\
\hline I & $9(60.0)$ & $11(73.3)$ & \multirow{2}{*}{0.301} \\
\hline II & $6(40.0)$ & $4(26.7)$ & \\
\hline FEVI / FVC, $($ Mean + SD) & $84.3 \pm 4$ & $85.9 \pm 3.5$ & 0.288 \\
\hline $\mathrm{PaO} 2,($ Mean + SD) & $83.1 \pm 4.2$ & $83 \pm 3.7$ & 0.968 \\
\hline \multicolumn{4}{|l|}{ D.M, n (\%) } \\
\hline Yes & $9(60.0)$ & $8(53.3)$ & \multirow{2}{*}{0.501} \\
\hline No & $6(40.0)$ & $7(46.7)$ & \\
\hline \multicolumn{4}{|l|}{ Serum albumin, $n$ (\%) } \\
\hline $3-3.5$ & $8(53.3)$ & $6(40.0)$ & \multirow{3}{*}{0.166} \\
\hline $3.5-4$ & $7(46.7)$ & $(33.3)$ & \\
\hline$>4$ & $0(0)$ & $4(26.7)$ & \\
\hline \multicolumn{4}{|l|}{ Haemoglobin, n (\%) } \\
\hline $10-12$ & $10(66.7)$ & $9(60.0)$ & \multirow{3}{*}{0.659} \\
\hline $12-14$ & $5(33.3)$ & $5(33.3)$ & \\
\hline$>14$ & $0(0)$ & $1(6.7)$ & \\
\hline \multicolumn{4}{|l|}{ Dysphagia, n (\%) } \\
\hline Yes & $11(73.3)$ & $11(73.3)$ & \multirow{2}{*}{0.591} \\
\hline No & $4(24.7)$ & $4(24.7)$ & \\
\hline \multicolumn{4}{|l|}{ Tumor histology, n (\%) } \\
\hline Adenocarcinoma & $11(73.3)$ & $11(73.3)$ & \multirow{2}{*}{0.659} \\
\hline Squamous Cell carcinoma & $4(24.7)$ & $4(24.7)$ & \\
\hline
\end{tabular}

BMI: Body mass index. ASA: American Society of Anesthesiologists. NYHA: New York Heart Association. FEV1: forced expiratory volume in one second. FVC: forced vital capacity. PaO2: partial pressure of oxygen tension. DM: diabetes mellitus. 
cant reduction in the duration of mechanical ventilation in GII (276.8 + $11.4 \mathrm{~min}$.) in comparison to GI (287.7 $+16.5 \mathrm{~min}$.) $(P=0.04)$ (Table 2$)$.

There were significant reductions in heart rate and MAP in Gll during the intraoperative period, at $\mathrm{T}_{\mathrm{abdo}}$
Tolv 15, and Tolv End $(P<0.05)$ (Figs. 1,2$)$. The mean of heart rate values showed a significant reduction in GII over the 72 hours post-operatively in comparison to $\mathrm{Gl}$ $(P=0.001)$ (Fig. 3).

The mean SBP values was significantly lower in GII

Table 2. Intra-operative data.

\begin{tabular}{|l|c|c|c|}
\hline & GI & GII & P value \\
\hline Surgery duration (min) & $269+20.9$ & $270.7+20.4$ & 0.629 \\
\hline One lung ventilation duration (min) & $90.7 \pm 16.7$ & $91 \pm 17.2$ & 0.958 \\
\hline Mechanical ventilation duration (min) & $287.7 \pm 16.5$ & $276.8 \pm 11.4$ & 0.044 \\
\hline Blood loss (mL) & $680 \pm 260.4$ & $650 \pm 271.2$ & 0.762 \\
\hline Blood transfusion (ml) & $853.3 \pm 313.7$ & $866.7 \pm 347.8$ & 0.913 \\
\hline Fluid administration (mL) & $2540 \pm 581.6$ & $2466.7 \pm 611.4$ & 0.744 \\
\hline Urine output (mL) & $374.7 \pm 89.3$ & $385.3 \pm 142.1$ & 0.800 \\
\hline
\end{tabular}

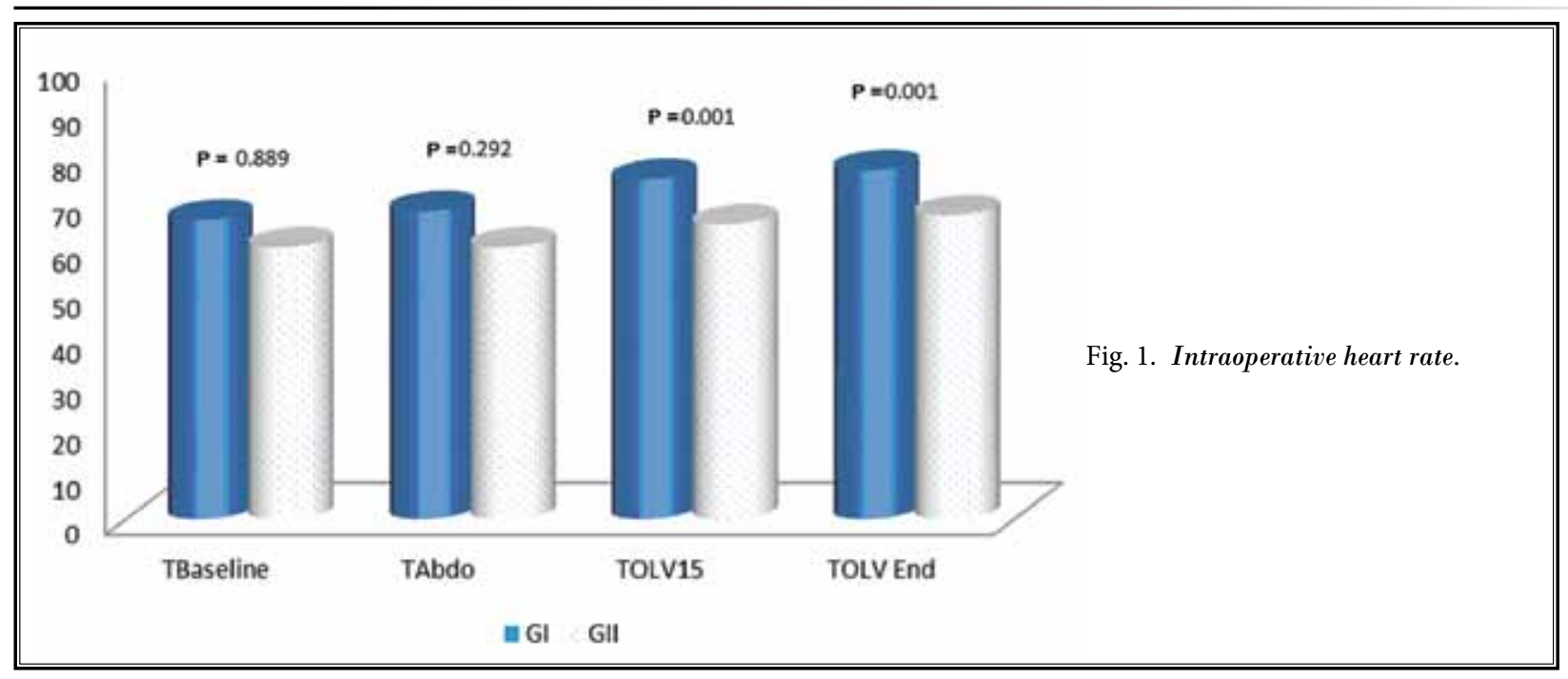

Fig. 2. Intraoperative $M A P$.

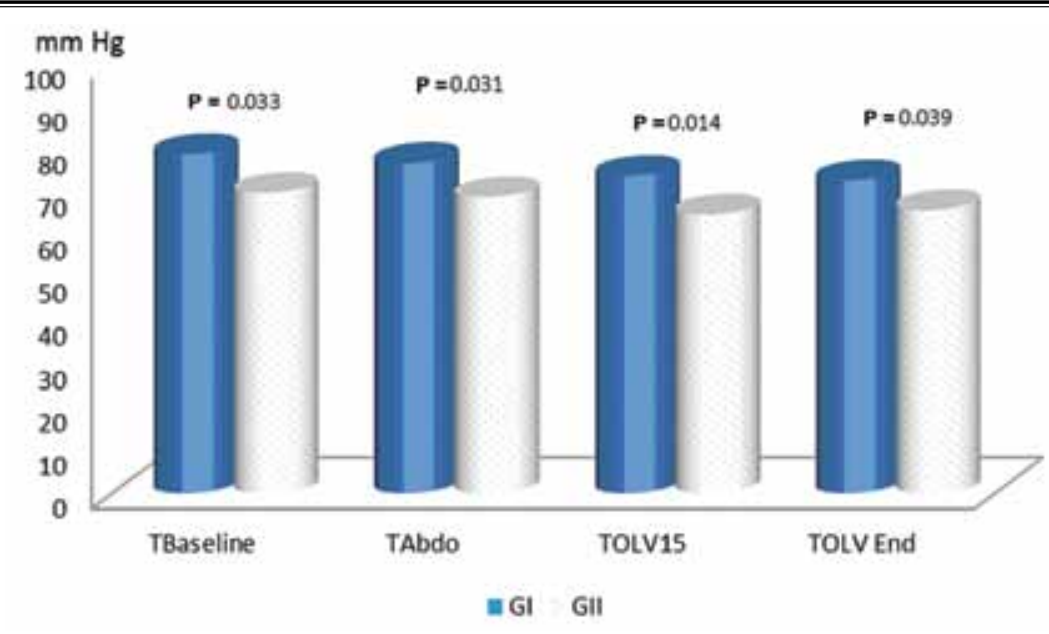


over the 72 hours post-operatively in comparison to $\mathrm{Gl}$ $(P=0.001)$ (Fig. 4). The mean DBP showed a significant reduction in Gll for 16 hours post-operatively compared with $\mathrm{Gl}(P=0.001)$ (Fig. 5).

The mean resting and dynamic VAS scores were significantly reduced in GII at all time periods studied in

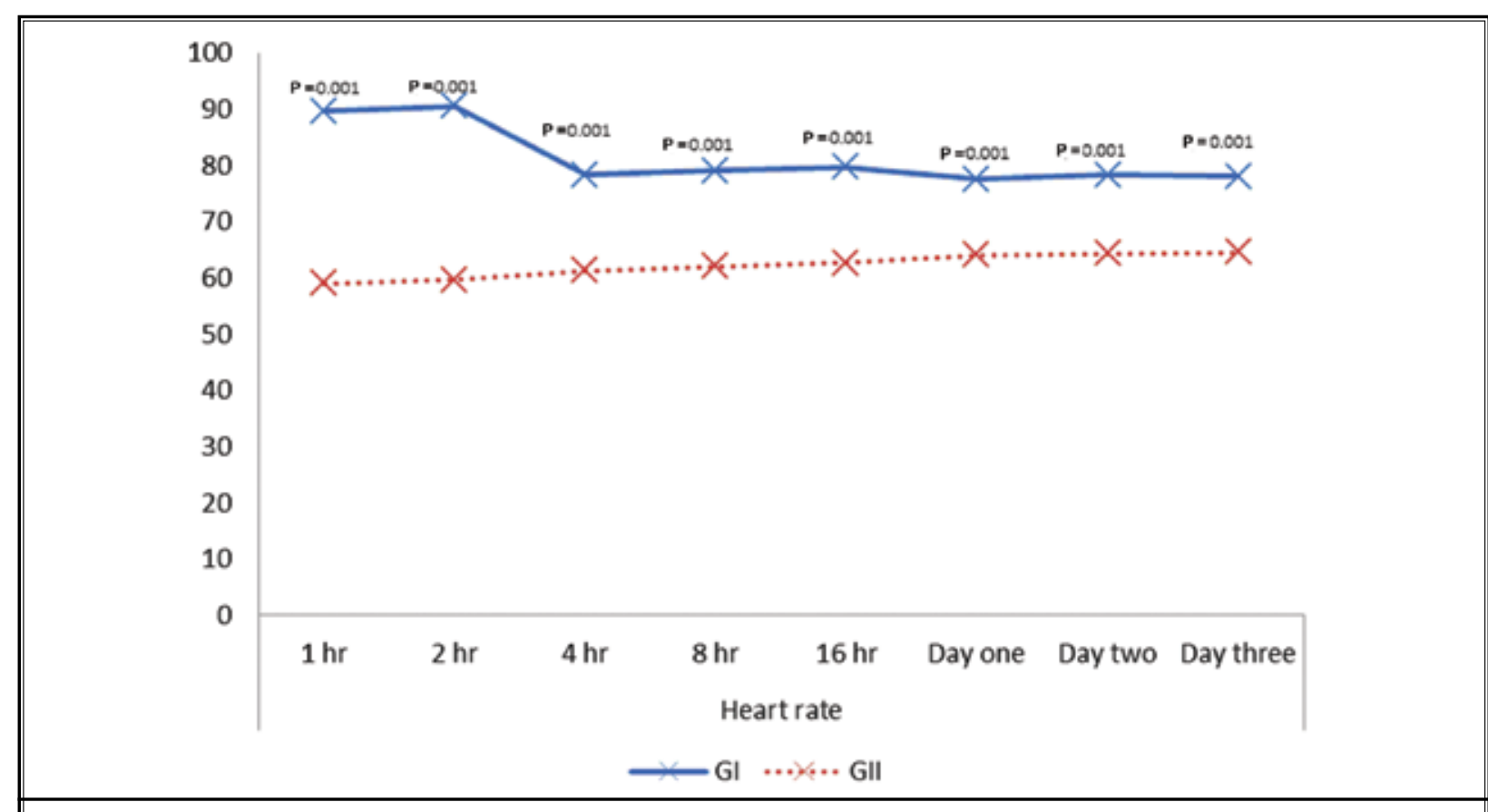

Fig. 3. Postoperative heart rate.

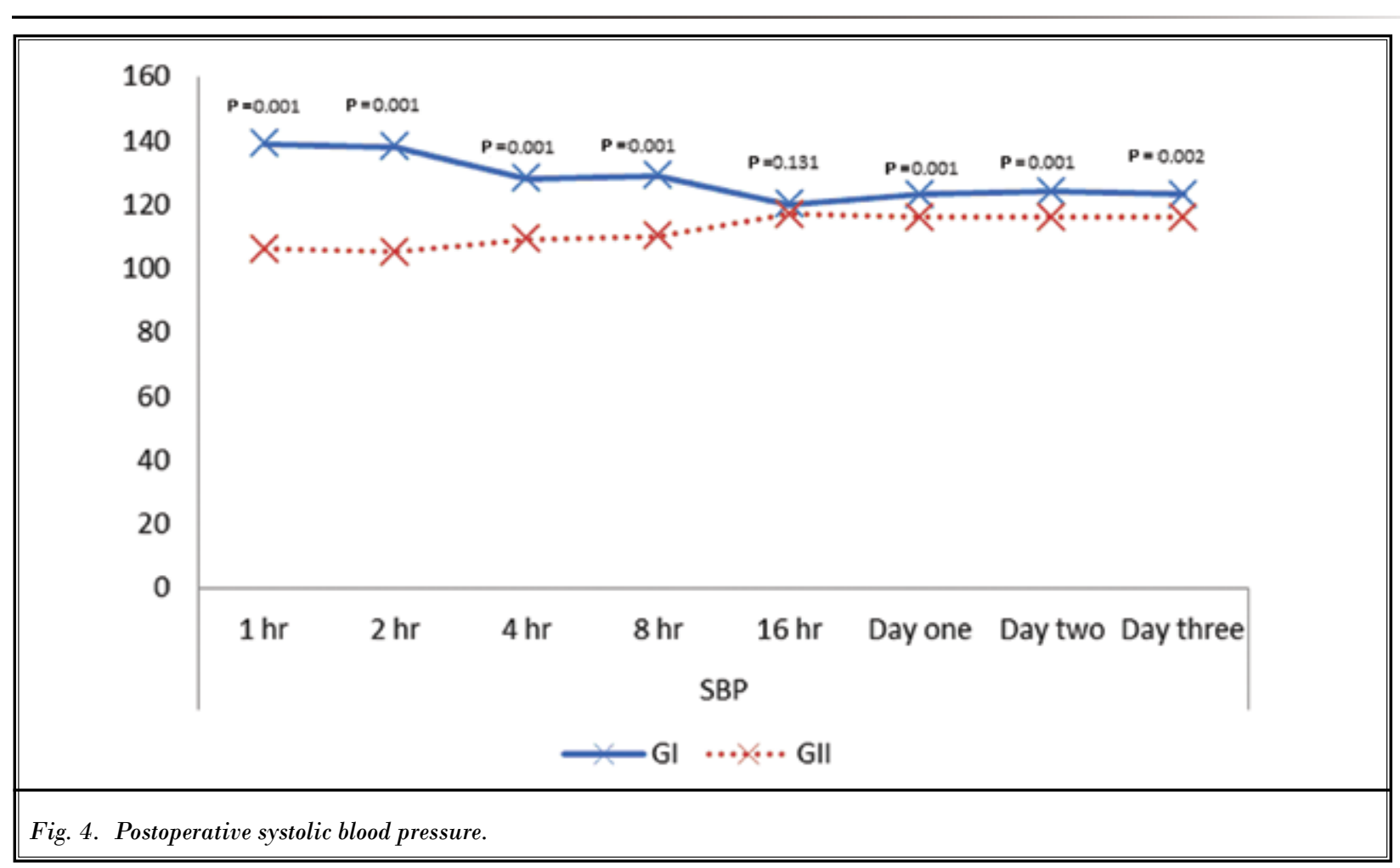



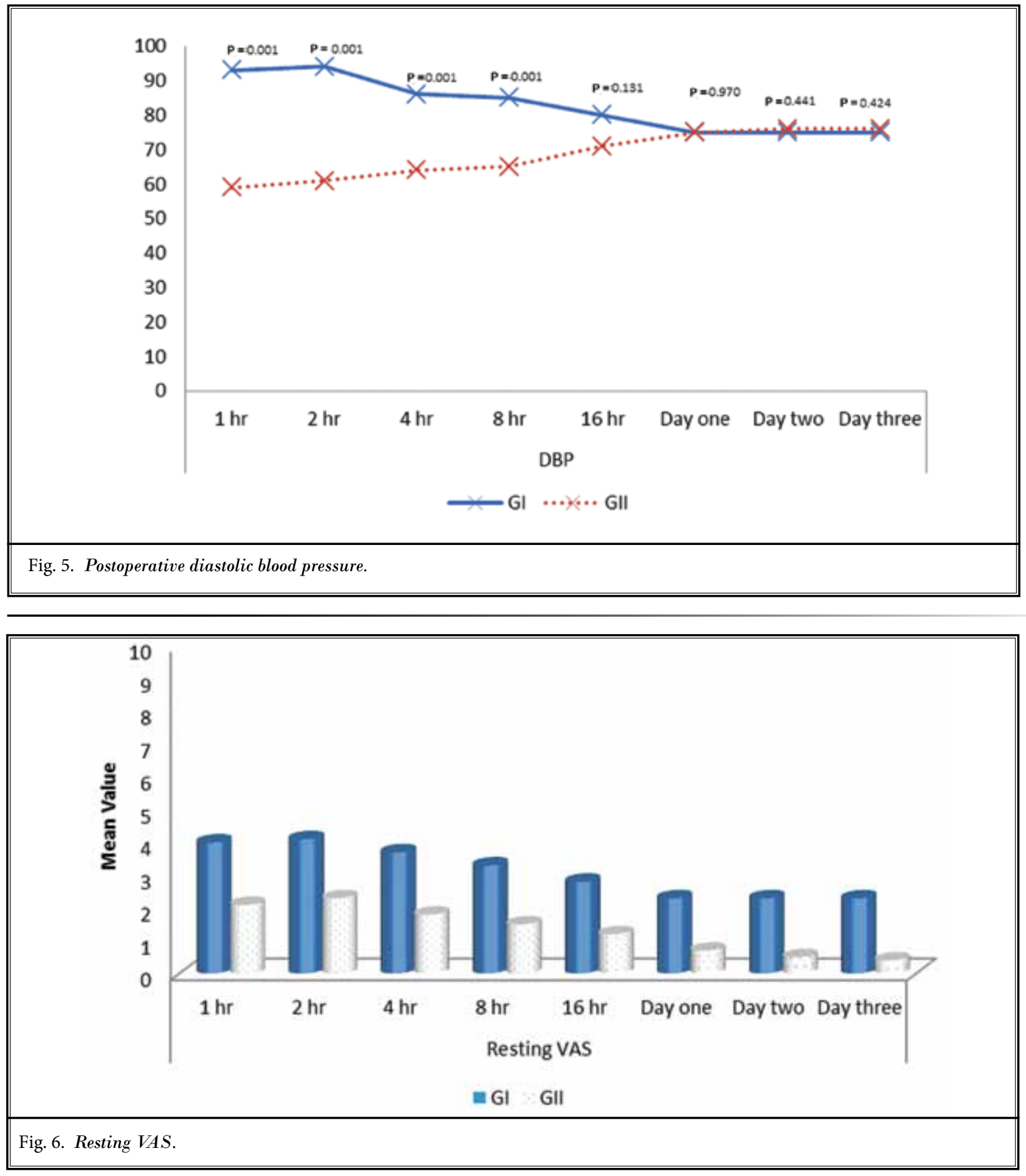

comparison to $\mathrm{Gl}(P=0.001)$ (Figs. 6, 7).

Daily PCA morphine consumption was markedly decreased in GII in comparison to $\mathrm{Gl}$ in the first 72 hours post operatively $(P=0.001)$ (Table 3 ).

Analysis of variance revealed that there were sig- nificant increases in blood level of IL- 6 and IL-8 over all the time period in both groups in comparison to baseline values $(P=0.001)$, However there were significant reductions in blood level of IL- 6 and IL- 8 in GII in comparison to $\mathrm{G} 1$ over all the study period $(P<0.05)$ (Tables 4,5$)$. 


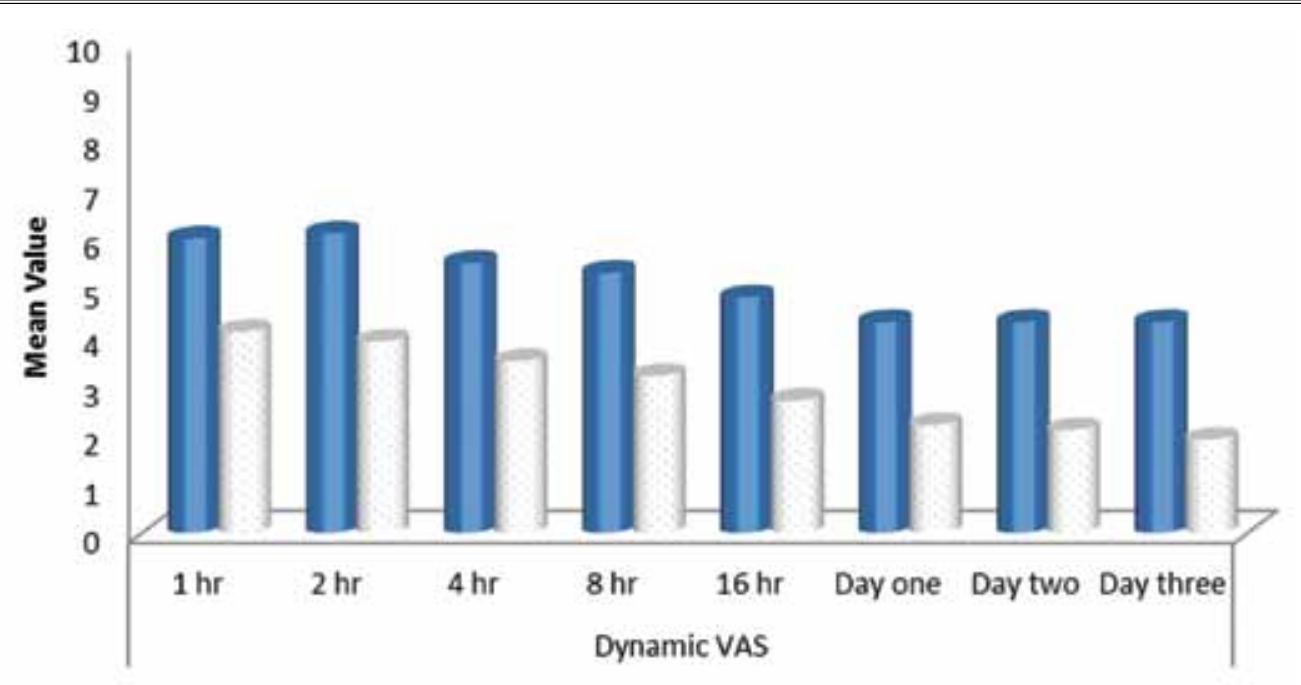

= GI GII

Fig. 7. Dynamic VAS.

Table 3. Post-operative morphine consumption (mg).

\begin{tabular}{|l|c|c|c|}
\hline & GI & GII & P value \\
\hline Post-operative day 1 & $41.9 \pm 7.9$ & $8.7 \pm 5.1$ & 0.001 \\
\hline Post-operative day 2 & $36.7 \pm 13.8$ & $5.1 \pm 4.3$ & 0.001 \\
\hline Post-operative day 3 & $19.6 \pm 6.1$ & $2.8 \pm 3.7$ & 0.001 \\
\hline
\end{tabular}

Table 4. Interleukin 6 ( $\mathrm{pg} / \mathrm{mL})$.

\begin{tabular}{||c|c|c|c||}
\hline & GI & GII & P value \\
\hline $\mathrm{T}_{\text {Baseline }}$ & $7 \pm 2$ & $6.5 \pm 2$ & 0.499 \\
\hline $\mathrm{T}_{\text {Abdo }}$ & $53.6 \pm 12.2^{\star}$ & $33 \pm 6.1^{*}$ & 0.001 \\
\hline $\mathrm{T}_{\text {Olv End }}$ & $111.5 \pm 16.5^{*}$ & $81 \pm 10.4^{*}$ & 0.047 \\
\hline $\mathrm{T}_{\text {postopl hr }}$ & $218.3 \pm 10.5^{*}$ & $123.9 \pm 14^{*}$ & 0.001 \\
\hline $\mathrm{T}_{\text {postop 20 hr }}$ & $80.6 \pm 13.7^{*}$ & $55.2 \pm 24.6^{*}$ & 0.033 \\
\hline
\end{tabular}

* Significant compared with $\mathrm{T}_{\text {Baseline }}$ at $P$ value $<0.01$

$\mathrm{T}_{\text {Baseline }}=$ baseline time after anesthetic induction and before ventilatory strategy application. $\mathrm{T}_{\text {Abdo }}=$ at the end of abdominal stage of operation. $\mathrm{T}$ oLv End $=$ at the end of one lung ventilation. $\mathrm{T}_{\text {Postop } 1}=$ one hour after the end of the surgical procedure. $\mathrm{T}_{\text {Postop } 20}=20$ hours after the end of the surgical procedure.

Six patients $(40 \%)$ in $\mathrm{Gl}$ and 2 patients $(13.3 \%)$ in GIl exhibited pneumonia. Pleural effusion developed in 4 patients $(26.7 \%)$ in $\mathrm{Gl}$ and one patient $(6.7 \%)$ in GII. Two patients (13.3\%) in $\mathrm{Gl}$ had adult respiratory distress syndrome (ARDS). Arrhythmias developed in 4 patients $(26.7 \%)$ in $\mathrm{Gl}$ and one patient $(6.7 \%)$ in Gll with a nonsignificant difference in the incidence of post-operative adverse effects noted between the 2 groups $(P>0.05)$ (Table 6). Post-operative mortality occurred in 4 patients $(26.7 \%)$ in $\mathrm{Gl}$ and one patient $(6.7 \%)$ in GII $(P>$ 0.05) (Table 6).

The duration of stay in PACU was significantly decreased in GII ( $10 \pm 2$ days) compared to GI $(15 \pm 3$ days $)$ $(P=0.001)$ (Table 6). 
Table 5. Interleukin 8 ( $\mathrm{pg} / \mathrm{mL})$.

\begin{tabular}{|l|c|c|c||}
\hline & GI & GII & P value \\
\hline $\mathrm{T}_{\text {Baseline }}$ & $6 \pm 1$ & $5.3 \pm 1$ & 0.065 \\
\hline $\mathrm{T}_{\text {Abdo }}$ & $25.8 \pm 3.2^{*}$ & $12.1 \pm 1.4^{\star}$ & 0.001 \\
\hline $\mathrm{T}_{\text {Olv End }}$ & $34.1 \pm 8.1^{*}$ & $24.4 \pm 3.2^{*}$ & 0.010 \\
\hline $\mathrm{T}_{\text {postop hr }}$ & $43.5 \pm 8.7^{*}$ & $34.2 \pm 2.7^{\star}$ & 0.013 \\
\hline $\mathrm{T}_{\text {postop 20 hr }}$ & $18.5 \pm 4.9^{*}$ & $11.7 \pm 1.4^{*}$ & 0.002 \\
\hline
\end{tabular}

* Significant compared with $\mathrm{T}_{\text {Baseline }}$ at $P$ value $<0.01$

$\mathrm{T}_{\text {Baseline }}=$ baseline time after anesthetic induction and before ventilatory strategy application. $\mathrm{T}_{\mathrm{Abdo}}=$ at the end of abdominal time. $\mathrm{T}_{\mathrm{OVV}} \mathrm{End}=$ at the end of one lung ventilation. $\mathrm{T}_{\text {Postop 1 }}=$ one hour after the end of the surgical procedure. $\mathrm{T}_{\text {Postop 20 }}=20$ hours after the end of the surgical procedure.

Table 6. Outcome of patients.

\begin{tabular}{|c|c|c|c|c|c|}
\hline & \multicolumn{2}{|c|}{ GI } & \multicolumn{2}{|c|}{ GII } & \multirow{2}{*}{$P$ value } \\
\hline & No. & $\%$ & No. & $\%$ & \\
\hline Pneumonia & 6 & 40.0 & 2 & 13.3 & 0.107 \\
\hline Pleural effusion & 4 & 26.7 & 1 & 6.7 & 0.163 \\
\hline ARDS & 2 & 13.3 & 0 & 0.0 & 0.232 \\
\hline Arrhythmias & 4 & 26.7 & 1 & 6.7 & 0.163 \\
\hline Anastomotic leak & 4 & 26.7 & 1 & 6.7 & 0.163 \\
\hline Surgical reintervention & 0 & 0.0 & 1 & 6.7 & 0.501 \\
\hline Myocardial ischaemia & 2 & 13.3 & 0 & 0.0 & 0.232 \\
\hline Septic shock & 2 & 13.3 & 1 & 6.7 & 0.501 \\
\hline Renal failure & 2 & 13.3 & 1 & 6.7 & 0.501 \\
\hline PACU duration (days) $($ Mean \pm SD) & \multicolumn{2}{|c|}{$15 \pm 3$} & \multicolumn{2}{|c|}{$10 \pm 2$} & 0.001 \\
\hline Post- operative mortality & 4 & 26.7 & 1 & 6.7 & 0.163 \\
\hline
\end{tabular}

ARDS $=$ Adult respiratory distress syndrome PACU $=$ post anesthesia care unit.

\section{Discussion}

This study showed that TEA reduced the systemic pro-inflammatory response and provided optimal post-operative pain relief. There was a trend towards improving the outcome of the patients in GII but it did not reach statistical significance. A number of factors may be responsible for the development and severity of inflammatory reactions during OLV. The ischemia/ reperfusion trigger an inflammatory response that may lead to lung injury (10). In the ventilated lung during OLV, high oxygen concentrations are necessary to maintain adequate oxygenation, producing reactive oxygen species and subsequently triggering inflammatory reactions $(11,12)$. Additionally, mechanical ventilation can cause mechanical stress on alveolar walls known as barotrauma or volutrauma, initiating a cytokine response $(13,14)$. Modification of this inflammatory response with a perioperative administration of steroids, prostaglandin E1, or a protease inhibitor may be useful. A reduction in hypercytokinemia, improved post-operative oxygenation, and shortened systemic inflammatory response (SIR) were reported (15-17).

In our study we have measured IL- 6 and IL- 8 because the prolonged half-life of IL- 6 has made this cytokine a precious indicator of both duration and extent of surgical injury (18). Also, IL-8 is one of the most important cytokines responsible for the recruitment of inflammatory cells to the alveoli. It is increased in the bronchoalveolar lavage fluid (BAL) of patients with acute respiratory distress syndrome, sepsis, and multiorgan failure (15). Tumor necrosis factor -a (TNF-a), IL-1b, 
IL-6, and IL-8 have been strongly implicated as mediators of sepsis and studies of sepsis have shown elevated circulating levels of these cytokines. Furthermore, raised levels of pro-inflammatory cytokines generally appear to correlate with severity of illness and outcome $(19,20)$. Also, high plasma concentrations of IL-6 in response to major surgery appear to be associated with post-operative mortality (21).

After the esophagectomy procedure, TEA has been shown to provide the most satisfactory analgesia and to reduce the incidence of both fatal and non-fatal respiratory complications $(22,23)$. Moreover it has been suggested recently that TEA can decrease the occurrence of anastomotic leakage after esophagectomy (24) and after operations on the upper gastrointestinal tract (25). These beneficial effects of TEA may result partly from an increase of blood flow in the gastric tube $(26,27)$. In our study there was a significant reduction in the mean rest and dynamic VAS scores in patients received TEA. Although TEA has many beneficial effects, we observed a significant reduction in the heart rate and blood pressure during intraoperative and post-operative periods. This is in agreement with Rudin and colleagues (28) who found that epidural anesthesia had a lower blood pressure that necessitated fluid and inotropic support.

In the current study we observed a significant reduction in IL-6 and IL-8 in GIl when compared to GI. Hong and colleagues (29) found less production of cytokines in patients undergoing colonic surgery receiving TEA with lidocaine versus IV lidocaine. Kato and colleagues (30) found that pro-inflammatory cytokines increased during major abdominal surgery in patients when combined with general and epidural anesthesia. Also Yokoyama and colleagues (31) have reported that combined general and epidural anesthesia in patients undergoing radical esophagectomy do not attenuate stress-induced cytokine production. Cai et al (32) re- ported that pre-emptive epidural analgesia combined with post-operative epidural analgesia provides more satisfactory pain relief and more effectively prevents IL-6 increases than only post-operative epidural analgesia or IV analgesia after gasterectomy for gastric carcinoma. It was reported that the sympathetic nervous system could produce IL- 6 and responded to it in an autocrine or paracrine manner (33). So our results are consistent with this explanation.

Pro-inflammatory cytokines were found to be high in ARDS patients, also it has been considered as a predictive of occurrence of ARDS. Although TEA reduced pro-inflammatory cytokines, the occurrence of ARDS was not reduced significantly in GIl compared to GI $(13.3 \%$ vs. $0.0 \%)$, also TEA reduced the occurrence of pneumonia and anastomotic leakage (GII vs. GI) (40\% vs. $13 \%$ ) (26.7 vs. 6.7$)$, respectively. but did not result in statistically significant data. A larger sample size is required to prove statistically significant data. TEA reduced the PACU stay $(P<0.001)$.

\section{Study Limitations}

This study is limited by its sample size, also we measured plasmatic cytokines but we did not directly measure pulmonary cytokines, so we cannot judge that TEA reduced systemically released cytokines or pulmonary released cytokines. It also lacks the long term follow-up of patients for chronic post-thoracotomy pain.

\section{Conclusion}

Our study concluded that TEA reduced the systemic pro-inflammatory response and provided optimal postoperative pain relief. Although there were no significant differences in adverse events, there was a trend towards improved outcome. Further clinical studies with larger numbers of patients are required.

\section{References}

1. Fujita $\mathrm{H}$, Kakegawa $\mathrm{T}$, Yamana $\mathrm{H}$, Shima I, Toh Y, Tomita Y, Fujii T, Yamasaki K, Higaki K, Noake T. Mortality and morbidity rates postoperative course, quality of life, andprognosis after extended radical lymphadenectomy for esophageal cancer. Ann Surg 1995; 222:652-662.

2. Tsurumaru M, Kajiyama $\mathrm{Y}$, Udagawa $\mathrm{H}$, Akiyama $\mathrm{H}$. Outcome of extended lymph node dissection for squamous cell carcinoma of the thoracic esopha- gus. Ann Thorac Cardiovasc Surg 2001; 7:325-329.

3. McCulloch P, Ward J, Tekkis PP, for the ASCOT Group of Surgeons. Mortality and morbidity in gastro-oesophageal cancer surgery: Initial results of ASCOT multicentre prospective cohort study. BJM 2003; 327:1192-1197.

4. Michelet $P$, D'Journo XB, Roch A, Doddoli C, Marin V, Papazian L, Decamps I, Bregeon F, Thomas P, Auffray JP. Protec- tive ventilation influences systemic inflammation after esophagectomy. Anesthesiology 2006; 105:911-919.

5. Wrigge $H$, Uhlig $U$, Zinserling J, Behrends-Callsen E, Ottersbach $G$, Fischer M, Uhlig S, Putensen C. The effects of different ventilatory settings on pulmonary and systemic inflammatory responses during major surgery. Anesth Analg 2004; 98:775-781.

6. Schenk MR, Putzier M, Kugler B, Tohtz 
S, Voigt K, Schink T, Kox WJ, Spies C, Volk T. Postoperative analgesia after major spine surgery: Patient-controlled epidural analgesia versus patient-controlled intravenous analgesia. Anesth Analg 2006; 103:1311-1317.

7. Basedovsky HO, Del Rey A. Immuneneuro-endocrine interactions: Facts and hypotheses. Endocr Rev 1996; 17:64-102.

8. Tsuji H, Asoh T, Takeuchi Y, Shirasaka C. Attenuation of adrenocortical response to upper abdominal surgery with epidural blockade. Br J Surg 1983; 70:122-124.

9. Hjortso NC, Christensen NJ, Andersen $\mathrm{T}$, Kehlet $\mathrm{H}$. Effects of the extradural administration of local anaesthetic agents and morphine on the urinary excretion of cortisol, catecholamines and nitrogen following abdominal surgery. $\mathrm{Br} \mathrm{J}$ Anaesth 1985; 57:400-406.

10. Jordan S, Mitchell JA, Quinlan GJ, Goldstraw $P$, Evans TW. The pathogenesis of lung injury following pulmonary resection. Eur Respir ] 2000; 15:790-799.

11. Baudouin SV. Lung injury after thoracotomy. Br J Anaesth 2003; 91:132-142.

12. Li LF, Liao SK, Ko YS, Lee CH, Quinn DA. Hyperoxia increases ventilator-induced lung injury via mitogen-activated protein kinases: A prospective, controlled animal experiment. Crit Care 2007; 11:R25.

13. Dos Santos CC, Slutsky AS. Invited review: Mechanisms of ventilator-induced lung injury: A perspective. J Appl Physiol 2000; 89:1645-1655.

14. Tandon S, Batchelor A, Bullock R, Gascoigne A, Griffin M, Hayes N, Hing J, Shaw I, Warnell I, Baudouin SV. Perioperative risk factors for acute lung injury after elective oesophagectomy. $\mathrm{Br}$ ] Anaesth 2001; 86:633-638.

15. Nakazawa K, Narumi Y, Ishikawa S, Yokoyama K, Nishikage T, Nagai K, Kawano T, Makita K. Effect of prostaglandin E1 on inflammatory responses and gas exchange in patients undergoing urgery for oesophageal cancer. $\mathrm{Br} J$ Anaesth 2004; 93:199-203.

16. Farrokhnia E, Makarem J, Khan ZH, Mohagheghi $M$, Maghsoudlou M, Abdollahi $A$. The effects of prostaglandin Er on interleukin-6, pulmonary function and postoperative recovery in oesophagect- omised patients. Anaesth Intensive Care 2009; 37:937-943.

17. Kawahara Y, Ninomiya I, Fujimura T, Funaki $\mathrm{H}$, Nakagawara $\mathrm{H}$, Takamura $\mathrm{H}$, Oyama K, Tajima H, Fushida S, Inaba H, Kayahara M. Prospective randomized controlled study on the effects of perioperative administration of a neutrophil elastase inhibitor to patients undergoing video-assisted thoracoscopic surgery for thoracic esophageal cancer. Dis Esophagus 2010; 23:329-339.

18. Blackwell T S, Christman JW. Sepsis and cytokines: Current status. $\mathrm{Br}$ J Anaesth 1996; 77:110-177.

19. Bown MJ, Nicholson ML, Bell PRF, Sayers RD. Cytokines and inflammatory pathways in the pathogenesis of multiple organ failure following abdominal aortic aneurysm repair. Eur ] Vasc Endovasc Surg 2001; 22:485-495.

20. Mcbrid WT, Armstrong MA, Mcbride SJ. Immunomodulation: An important concept in modern anaesthesia. Anaesthesia 1996; 51:465-473

21. Kooguchi K, Kobayashi A, Kitamura $Y$, Ueno $\mathrm{H}$, Urata $\mathrm{Y}$, Onodera $\mathrm{H}$, Hashimoto $\mathrm{S}$. Elevated expression of inducible nitric oxide synthase and inflammatory cytokines in the alveolar macrophages after esophagectomy. Crit Care Med 2002; 30:71-76.

22. Flisberg P, Rudin A, Linner R, Lundberg $J$. Pain relief and safety after major surgery. A prospective study of epidural intravenous analgesia in 2696 patients. Acta Anaesthesiol Scand 2003; 47:457-465.

23. Chandrashekar MV, Irving M, Wayman J, Raimes SA, Linsley A. Immediate extubation and epidural analgesia allow safe management in a high-dependency unit after two-stage oesophagectomy. Results of eight years of experience in a specialized upper gastrointestinal unit in a district general hospital. $\mathrm{Br}$ J Anaesth 2003; 90:474-479.

24. Michelet P, D'Journo XB, Roch A, Papazian L, Ragni J, Thomas P, Auffray JP. Perioperative risk factors for anastomotic leakage after esophagectomy: Influence of thoracic epidural analgesia. Chest 2005; 128:3461-3466.

25. Zugel N, Bruer C, Breitschaft K, Angster $R$. Effect of thoracic epidural analgesia on the early postoperative phase after interventions on the gastrointestinal tract. Chirurg 2002; 73:262-268.

26. Kabon B, Fleischmann E, Treschan T, Taguchi A, Kapral S, Kurz A.Thoracic epidural anesthesia increases tissue oxygenation during major abdominal surgery. Anesth Analg 2003; 97:1812-1817.

27. Lázár G, Kaszaki J, Abrahám S, Horváth G, Wolfárd A, Szentpáli K, Paszt A, Balogh A, Boros M. Thoracic epidural anesthesia improves the gastric microcirculation during experimental gastric tube formation. Surgery 2003; 134:799-805.

28. Rudin A, Flisberg P, Johansson J, Walther B, Lundberg C). Thoracic epidural analgesia or Intravenous morphine analgesia after thoracoabdominal esophagectomy: A prospective follow-up of 201 patients. Journal of Cardiothoracic and Vascular Anesthesia 2005; 19:350-357.

29. Hong JY, and Kyung T. Lim KT. Effect of preemptive epidural analgesia on cytokine response in laparoscopic radical hysterectomy for cervical cancer. Reg An Ceresth Pain Med 2008; 33:44-51.

30. Kato M, Suzuki H, Murakami M, Akama M, Matsukawa S, Hashimoto Y. Elevated plasma levels of interleukin-6, interleukin- 8, and granulocyte colony-stimulating factor during and after major abdominal surgery. J Clin Anesth 1997; 9:293-298.

31. Yokoyama M, Itano $\mathrm{Y}$, Katayama $\mathrm{H}$, Morimatsu H, Takeda Y, Takahashi T, Nagano O, Morita K. The effects of continuous epidural anesthesia and analgesia on stress response and immune function in patients undergoing radical esophagectomy. Anesth Analg 2005; 101:1521-1527.

32. Cai $X H$, Wang SP, Chen XT, Peng, SL, Cao MH, Ye XJ, Yang, YZ. Comparison of three analgesic methods for postoperative pain relief and their effects on plasma interleukin-6 concentration following radical surgery for gastric carcinoma. Nan Fang, Yi Ke Da Xue Xue Bao 2007; 27:387-389.

33. Marz P, Cheng JG, Gadient RA, Patterson $\mathrm{PH}$, Stoyan $\mathrm{T}$, Otten $\mathrm{U}$, Rose-John $S$. Sympathetic neurons can produce and respond to interleukin 6. Proc Natl Acad Sci USA 1998; 95:3251-3256. 
